




\section{FORMAÇÃO INICIAL E PRÁTICA DOCENTE: PERCEPÇÕES DE FUTURAS PROFESSORAS}

\section{INITIAL TEACHER EDUCATION AND TEACHING PRACTICE: FUTURE TEACHERS' PERCEPTIONS}

Sydione Santos*

Resumo: O artigo focaliza a formação inicial de professores e sua relação com a prática docente. Socializa-se a reflexão sobre os dados preliminares de uma investigação, cujo objetivo é analisar como futuras professoras, acadêmicas do curso de Pedagogia, descrevem e compreendem o processo de ensino e aprendizagem, a partir de suas vivências em classes de alfabetização. Esta pesquisa é desenvolvida a partir do trabalho realizado no contexto do Programa de Bolsas de Iniciação à Docência - PIBID e fundamenta-se em teorias sobre saberes docentes, reflexividade e investigação-ação. Na primeira fase da investigação, foi realizado um estudo exploratório e interpretativo, utilizando-se das narrativas como fonte de coleta de dados. Os dados iniciais indicaram as potencialidades dos processos formativos vivenciados, apontando a emergência de uma atitude reflexiva e investigativa na docência. Conclui-se também que a observação, a tematização e a problematização da experiência são processos articulados e inerentes à prática docente, portanto, devem ser oportunizados durante a formação acadêmicoprofissional (inicial) do professor.

Palavras-chave: Docência. Formação de Professores. Formação Inicial. Narrativas.

Abstract: This article focuses on teachers' initial education and its relation to teaching practice. It shares reflections about data obtained in a research aimed at analyzing how future teachers from the Pedagogy Course describe and understand the teaching and learning process taking into account their experiences in literacy classes. This research is carried out in the context of the Institutional Scholarship Program of Teacher Initiation (PIBID, in the Portuguese acronym), and it is supported by theories about teacher knowledge, reflexivity and action-research. The first phase of the investigation included an exploratory and interpretative study using narratives as sources of data generation. Initial data indicated the potential of the formative processes experienced, highlighting the emergence of a reflective and investigative attitude in teaching. It was also concluded that observation, thematization and problematization of experiences are processes articulated and inherent to the teaching practice, therefore, these processes should be provided during the initial professional-academic education of teachers.

Keywords: Teaching. Teacher Education. Initial Education. Narratives.

\footnotetext{
* Doutora em Educação pela UFSCar. Professora Adjunta da UEPG. E-mail: <sydione@terra.com.br>.

* Doctor in Education from UFSCar. Professor at UEPG. E-mail: <sydione@terra.com.br>.
} 


\section{Notas introdutórias}

Neste trabalho, tem-se como objetivo socializar parte de uma investigação desenvolvida sobre o percurso de futuras professoras, acadêmicas do curso de Pedagogia, de uma universidade pública, que participaram do Programa de Bolsas de Iniciação à Docência - PIBID. O referido programa apoia projetos de iniciação à docência em instituições de ensino superior, atendendo a uma das atribuições da CAPES (Coordenação de Aperfeiçoamento de Pessoal do Ensino Superior) de induzir e fomentar a formação inicial e continuada de profissionais do magistério. Nessa direção, o PIBID deve proporcionar a investigação de problemas vivenciados no processo ensino-aprendizagem e provocar a participação de futuros professores em práticas docentes de caráter inovador e interdisciplinar, buscando a superação qualitativa das questões identificadas. Espera-se ainda que as escolas públicas possam se tornar protagonistas nos processos formativos dos estudantes das licenciaturas, mobilizando seus professores como co-formadores de futuros professores.

Sendo assim, considera-se que os cursos de formação inicial são constituintes de um processo de desenvolvimento profissional que se constrói ao longo da vida e da carreira. Daí a necessidade de oportunizar aos futuros professores espaços e tempos que favoreçam a observação, a tematização e a problematização de experiências docentes, tornando-as fonte de aprendizagem e de conhecimento, além de contribuírem para a sua identificação com a profissão. Nesse contexto, inseriu-se o Projeto de Iniciação à Docência do Curso de Pedagogia da Universidade Estadual de Ponta Grossa, objeto deste trabalho.

O projeto do curso de Pedagogia foi realizado em duas escolas da rede públi- ca municipal de ensino e envolveu quinze acadêmicas bolsistas, três coordenadoras da universidade (professoras da área de pesquisa e prática pedagógica), duas supervisoras (professoras das escolas, também bolsistas), quinze turmas dos três primeiros anos do $1^{\circ}$ ciclo do Ensino Fundamental. O processo de alfabetização tornou-se o eixo temático do projeto, ou seja, o condutor que gerou interrogações e lançou o desafio da compreensão do processo de ensinar a ler e escrever. Buscou-se assim o entendimento das concepções e formas de alfabetizar suscitadas pelas práticas observadas, vivenciadas e investigadas. Compreende-se que nessa relação é que se fazem necessários os conceitos, que se inserem no amplo corpus de referencial teórico, os quais se tornam importantes ferramentas para contribuir na ressignificação da prática.

A metodologia desenvolvida no projeto de iniciação à docência constituiu-se de fases articuladas e que se desenvolveram em permanente interação, considerando as continuidades e rupturas, sendo estas:

a) observação participante - olhar atento e direcionado no e para o cotidiano da escola/ sala de aula, acompanhado de registros sistemáticos, tendo em vista a problematização de questões a serem investigadas;

b) projetos de intervenção - planejamento e execução de ações docentes a partir de observação participante; estas vivências constituíram-se em docências reflexivas, oportunizando a inserção e experiência direta nas acadêmicas em situações de ensino. A partir delas, desencadearam-se novas perguntas e percepções, conduzindo a uma investigação sistematizada;

c) desenvolvimento de um projeto de investigação-ação, a partir de um problema específico a ser estudado e enfrentado no campo de trabalho. 
O trabalho desenvolvido no PIBID desencadeou várias problematizações e possibilitou que também os formadores direcionassem o olhar para as necessidades formativas dos acadêmicos do curso de Pedagogia. Nessa direção, é que foi proposta a pesquisa aqui apresentada, cujo foco principal é o processo de iniciação à docência e sua relação com a formação acadêmico-profissional. A referida investigação foi provocada a partir das seguintes questões:

- Quais as relações entre os saberes oriundos do curso de formação inicial e a complexidade da educação escolar?

- Qual o significado dos saberes da formação para as futuras professoras?

- As futuras professoras manifestam compreensões em relação aos elementos que compõem a prática docente e o processo ensino-aprendizagem em função de suas experiências em classes de Alfabetização?

A partir desses questionamentos, busca-se analisar como as futuras professoras descrevem e compreendem o processo ensino-aprendizagem, a partir das vivências em classes de alfabetização. Nesse contexto, pretende-se também identificar a relação entre os saberes oriundos da formação inicial (acadêmico-profissional) e a prática docente, sob a ótica das bolsistas. Além disso, as conclusões a partir do referido estudo devem possibilitar a reflexão sobre o processo de formação de professores no curso de Pedagogia, considerando as necessidades formativas apontadas durante o desenvolvimento do projeto de iniciação à docência. mentos:

A pesquisa constitui-se de três mo-

1- Mapeamento, descrição e interpretação das narrativas em diários de campo, escritas durante a etapa de observação participante nas classes de alfabetização. Neste momento, tem-se o objetivo de identificar, nas primeiras narrativas, as preocupações, os questionamentos, as percepções das bolsistas e possíveis relações com o seu curso de formação.

2- Análise dos relatórios de intervenções (segunda fase do projeto de iniciação à docência). Tem-se o objetivo de analisar as reflexões das bolsistas, a partir de suas vivências planejadas nas classes em que estavam inseridas.

3- Análise dos artigos - síntese conclusiva sobre a trajetória, em que as bolsistas explicitam o desenvolvimento de uma proposta de investigação-ação, a partir dos problemas desencadeados durante as observações e vivências. Esta conclusão oportunizará a análise das relações que as bolsistas estabeleceram entre os diversos saberes docentes durante seu percurso.

No espaço deste texto, será socializada a reflexão sobre os dados oriundos do primeiro momento da pesquisa, já concluído, referente à etapa de observação participante das bolsistas nos contextos escolares. Nessa primeira fase, foram analisadas as narrativas escritas durante os meses iniciais do trabalho para aproximar-se do pensamento das bolsistas e planejar ações futuras no contexto do projeto de iniciação à docência. Primeiramente, será focalizada a docência, trazendo para a discussão alguns fundamentos teóricos da pesquisa; em seguida, os dados empíricos, mapeados nos diários de campo, serão abordados numa perspectiva descritiva, apontando-se reflexões sobre as percepções das bolsistas no que se refere à alfabetização, ao processo ensino-aprendizagem e à prática pedagógica.

Olhar de professor, Ponta Grossa, 15(2): 355-369, 2012. Disponível em <http://www.uepg.br/olhardeprofessor> 


\section{Docência e processos formativos: alguns enfoques teóricos}

A reflexão sobre o papel da escola na contemporaneidade e o trabalho docente está diretamente relacionada à formação inicial de professores, compreendida atualmente como formação acadêmico-profissional. Nesse contexto, discute-se a necessidade de os cursos de licenciatura aproximarem-se da complexidade da escola e dos aspectos que envolvem a docência. Assim, a aprendizagem profissional da docência e seu processo de iniciação tem sido um tema abordado no âmbito das pesquisas, tanto no que se refere às práticas formativas, quanto às políticas de formação de professores.

Nesse cenário, afirma-se o significado e a importância da formação inicial, pois esta faz parte de um continuum, de um processo de desenvolvimento profissional que permeia toda a vida e carreira. Assim sendo, torna-se necessário discutir de que modo a docência tem sido compreendida, que aspectos envolvem o processo de aprender a ensinar e a se tornar professor, como se constitui o conhecimento profissional docente. Nesse âmbito de discussão, encontram-se os estudos de Imbernón (2011); Mizukami et al (2002); Nóvoa (1991, 1992); Oliveira (2010); Roldão (2007); Tardif e Raymond (2000); Tardif (2002); Veiga (2008); entre outros.

Os estudiosos concordam que a docência é uma atividade profissional e requer formação especializada, ou seja, necessita de conhecimentos específicos para exercê-la adequadamente. (VEIGA, 2008). Nessa direção, Imbernón (2011) aponta que ser um profissional implica o domínio de uma série de habilidades especializadas que lhe permitem ser competente em um determinado trabalho. Discute ainda que os conhecimentos do professor são construídos e reconstruídos durante a vida profissional, ao serem relacionados com a teoria e a prática.
As pesquisas indicam que, devido à singularidade do ensino, a formação profissional do professor exige saberes específicos, sem que estes se desarticulem da prática educativa, entendida no sentido mais amplo. Ou seja, os saberes da formação precisam relacionar-se com as situações concretas de ensino e estas envolvem: a dinâmica dos alunos, as concepções dos professores, a organização e a cultura institucional, as políticas educacionais, o contexto sócio-político, entre outros aspectos.

Em consonância com tais posicionamentos, Roldão (2007) aponta um conjunto de fatores e agregadores que caracterizam o conhecimento profissional docente, constituindo-se de:

- capacidade analítica permanente, que se opõe à prática rotineira destituída de reflexão;

- mobilização e interrogação constante, devido à imprevisibilidade e singularidade das situações de ensino e das pessoas;

- meta-análise, que requer distanciamento da sua própria ação e autocrítica, considerando-se a contribuição dos conhecimentos que constituem o saber docente;

- comunicabilidade e circulação, que deveriam acontecer a partir da meta-análise, permitindo ao professor que o saber tácito torne-se articulado e sistematizado. Nesse caso, o conhecimento do professor pode ser comunicado, transmitido e discutido nas comunidades de pares e perante outros, pois sem esta possibilidade, perde-se, segundo a autora,

as infindáveis energias e progressos relevantes do conhecimento produzido pelos docentes [...], explicável entre outros factores, pelo praticismo que historicamente se associou à representação social do professor. (ROLDÃO, 2007, p. 101). 
É importante ainda perceber o caráter contextual e interativo da atividade docente. Nessa dimensão, a docência se constrói e se reconstrói pela interação cotidiana entre os sujeitos e tal processo demanda formas de pensar, sentir e agir que são mobilizadas no contexto da ação e da organização em que o profissional atua. Desse modo, o professor atribui significado ao seu trabalho através de suas experiências, que se integram a um conjunto de saberes e constituem sua base de conhecimento profissional.

Os estudos de Tardif (2002), realizados na perspectiva da sociologia das profissões, reforçam o caráter sócio prático da docência e contribuem para esta reflexão, apontando que o saber do professor precisa ser entendido num sentido amplo, pois envolve conhecimentos, hábitos e atitudes que estão intimamente ligados ao seu trabalho. $\mathrm{O}$ referido pesquisador ainda enfatiza que no âmbito da experiência se articulam os saberes práticos, operativos e normativos, relacionados às funções que os professores exercem na realização do seu ofício. Nesse caso, sua utilização depende de uma adequação às funções, aos problemas, às situações de trabalho e aos objetivos educacionais. Significa considerar que na e pela experiência, os professores selecionam, filtram, julgam e avaliam os diferentes saberes, incorporam à sua prática, negam ou os retraduzem em função dos contextos variáveis e contingentes da atividade cotidiana.

Nessa perspectiva, é importante analisar que a docência é uma atividade constituída por diferentes saberes, oriundos de diversas fontes, presentes na vida e carreira do professor. Tardif e Raymond (2000) e Tardif (2002) sinalizam que os saberes dos professores são plurais, heterogêneos e compósitos, decorrentes de fontes sociais diversas (família, escola, universidade, outras instituições...) e adquiridos em tempos sociais diferentes (infância, escola, formação profissional, carreira, prática docente na escola e relação com os pares...). Os saberes integram-se ao trabalho docente pelo seu uso e pela relação social com os grupos, instâncias e indivíduos que os produzem.

Torna-se necessário então refletir sobre o significado dos saberes da formação profissional, oriundos das instituições formadoras de professores e que se constituem a partir das ciências da educação, da ideologia pedagógica e das áreas específicas do conhecimento. Além disso, tais saberes só adquirem significado se contribuírem para a compreensão da trama de relações que envolvem a complexidade da educação escolar, com vistas a uma nova ação, superadora e qualitativamente diferente.

A partir das referidas análises, é importante compreender a formação docente numa perspectiva reflexiva e investigativa, buscando-se a interdependência entre estes dois processos. A reflexão é compreendida como processo de distanciamento para pensar a prática, iniciando-se uma atitude teórica sobre ela. No cotidiano, a reflexão ocorre, especialmente, a partir do diálogo com o conhecimento pessoal-individual e com o conhecimento de outros sujeitos (aprendizagem por observação, relação com colegas experientes, modelos da escolarização anterior etc.). No entanto, a reflexão não pode se limitar ao conhecimento intersubjetivo e necessita também ser orientada pelo conhecimento científico. Nesse caso, desencadeia-se uma reflexividade que se localiza na interação entre o conhecimento científico, o conhecimento pessoal e o conhecimento compartilhado, ligada às ações e à prática social. A ciência, como corpus de conhecimentos e elaborações culturais objetivas, pode transformar-se em instrumento de pensamento para diagnosticar, desvendar, criticar o conhecimento que o sujeito já possui, 
tornando-se ferramenta para a reflexão e novas ações (GIMENO SACRISTÁN, 1999).

Desse modo, refletir sobre o trabalho docente, nas suas diferentes dimensões, relaciona-se à necessidade de o profissional observar a própria prática, diagnosticar problemáticas, desconstruir crenças e valores, entrar em conflito diante do trabalho que realiza, rever sua base de experiências e conhecimento, analisar as consequências do ensino. Desenvolver a capacidade reflexiva demanda que ela seja materializada em "atitudes" de reflexão, destacando-se a necessidade de uma "atitude investigativa". Esta se constrói no percurso pessoal e profissional, precisa ser provocada e mantida, envolve tempos e espaços que promovam a construção de novas compreensões.

Nessa análise, o ensino reflexivo articula-se à pesquisa-ação, na perspectiva da pesquisa da e na prática. Concorda-se com Zeichner e seus colaboradores (1993, 2001, 2002, 2003) que os professores precisam ser concebidos como pesquisadores de sua prática e como sujeitos de um processo de construção de conhecimento. Nesse enfoque, devem realizar pesquisa-ação para melhorar suas práticas e para o seu próprio desenvolvimento profissional, aspectos que vão resultar na transformação da escola. Ao refletir sobre os temas do cotidiano docente, a compreensão do professor amplia-se pela possibilidade de confronto com outros conhecimentos, o que poderá respaldar o significado e a escolha de ações posteriores. Pela análise, crítica, reestruturação e incorporação de novos referenciais, há um processo de teorização por parte do professor, modificando o significado que a relação teoria-prática assume no paradigma da racionalidade técnica.

Para Imbernón (2011), a pesquisa da própria prática deve ser uma ferramenta de formação do professor e destaca que a pes- quisa-ação é uma perspectiva de investigação que parte do próprio docente, para ajudá-lo a buscar respostas para os problemas do ensino. Dessa forma, o profissional pode formular questões válidas sobre sua prática e prever objetivos para direcionar seu trabalho e enfrentar os problemas do ensino e da aprendizagem. O referido estudioso ainda afirma que este modelo formativo contribui para o professor atribuir sentido às suas experiências e aponta que

[...] esse processo de formação pode contribuir para mudar o conhecimento do professor (por ex., facilitando uma relação diferente entre ensino e aprendizagem), o pensamento (p. ex., favorecendo estratégias de resolução de problemas, aumentando sua capacidade cognitiva), melhorando as formas de comunicação e de tomada de decisões grupais. Quando atuam como pesquisadores, os professores têm mais condições de decidir quando e como aplicar os resultados da pesquisa que estão realizando; sua experiência os ajuda a colaborar mais uns com os outros e, por fim, eles aprendem a ser professores melhores, sendo capazes de transcender o imediato, o individual e o concreto. (2011, p. 80).

É importante analisar que a investigação da própria prática não é um processo individualista e isolado, envolve a necessidade da colaboração entre os sujeitos e a partilha de conhecimentos, incluindo o movimento entre a experiência e os diversos saberes. Assim, esse processo desencadeia a reflexividade localizada na interação entre as esferas do conhecimento pessoal, do conhecimento compartilhado (intersubjetivo) e do conhecimento científico. Além disso, é necessário afirmar que, ao combinar os processos investigativos com a prática de ensino, tornam-se possíveis alterações nos padrões de pensamento, na compreensão e na argumentação 
dos profissionais, desenvolvendo-se uma atitude crítico-reflexiva frente à profissão e ao contexto em que o ensino se concretiza: a prática social mais ampla.

De acordo com as concepções apontadas anteriormente, foi desenvolvido o processo formativo no PIBID - Pedagogia, gerando propostas investigativas das acadêmicas bolsistas, dos professores e coordenadores envolvidos, na relação com o trabalho docente na escola.

\section{A pesquisa: encaminhamentos metodológicos}

A presente pesquisa realiza-se num enfoque descritivo-interpretativo, compreendendo-se que este tipo de abordagem centra-se na relação entre os indivíduos e seus contextos, valorizando-se a atribuição de sentidos fornecida pelos sujeitos investigados e também pelos investigadores. Nesse caso, objetiva-se analisar os significados atribuídos pelas bolsistas ao longo do percurso de formação no projeto. O estudo envolve três momentos: mapeamento, descrição e interpretação das primeiras narrativas para identificar suas preocupações e percepções; análise dos relatórios das intervenções (vivências propostas ao longo do projeto); análise das sínteses finais (artigos), que relacionam também o processo de investigação de cada bolsista, realizado em função das problematizações oriundas das primeiras etapas. No presente artigo, apresenta-se a primeira fase do referido estudo longitudinal.

Os sujeitos da pesquisa foram constituídos por nove bolsistas que atuaram na escola A, distribuídos nos três primeiros anos do $1^{\circ}$ ciclo da alfabetização, ou seja, as classes de alunos com seis, sete e oito anos de idade.
Na primeira fase da pesquisa, foram utilizados como fonte de coleta de dados os diários de campo, cujas narrativas expressam a trajetória de aprendizagem durante a participação no programa de iniciação à docência, a versão que a futura professora imprime à sua participação, o estilo pessoal de enfrentamento das questões, a percepção que tem das experiências observadas e vivenciadas. Entende-se que os documentos pessoais tornam-se um significativo instrumento para se chegar ao pensamento do seu autor.

Pode-se inferir que quando o professor narra sua experiência, ele a reconstrói como discurso prático e como atividade profissional. A descrição é perpassada por proposições reflexivas, aparecem os porquês e as estruturas de racionalidade e de justificação sobre os fatos narrados. Assim, a narração desencadeia a reflexão (ZABALZA, 2004). É importante também destacar o caráter longitudinal dos documentos pessoais, quando estes são escritos durante um processo contínuo de formação profissional. Nesse caso, os diários evidenciam o transcorrer da ação e o desenvolvimento do pensamento ao longo de um transcurso, conservando a evolução e a atualidade dos dados, a continuidade e as rupturas necessárias ao movimento teórico-prático.

Torna-se necessário informar que os diários foram instrumentos de uso constante e contínuo das acadêmicas participantes do PIBID durante as observações, as docências reflexivas e o percurso de investigação-ação. As acadêmicas bolsistas deveriam registrar de modo livre as questões emergentes da prática docente, além de serem estimuladas a realizarem questionamentos em função dos aspectos abordados. Dessa forma, as narrativas foram balizadoras das discussões nas reuniões periódicas e, por meio delas, vieram à tona as problematizações que desencadearam os temas de estudo e o processo de

Olhar de professor, Ponta Grossa, 15(2): 355-369, 2012. Disponível em <http://www.uepg.br/olhardeprofessor> 
investigação-ação de cada bolsista nas classes de alfabetização.

Sendo assim, as narrativas escritas em diários de campo não foram somente utilizadas como ferramenta de pesquisa, mas especialmente, fizeram parte das estratégias formativas vivenciadas no projeto de iniciação à docência. Enquanto situação formativa, as narrativas possibilitam o distanciamento dos sujeitos sobre o observado e o vivido, tornando-se um meio para sistematizar o pensamento, desencadeando-se a reflexividade. Ao mesmo tempo em que o sujeito organiza as ideias para escrever o relato, ele pode reelaborar a experiência de modo reflexivo. Nesse caso, novos significados podem ser construídos, a partir do contraste com os diferentes saberes, compondo outras bases de compreensão do sujeito sobre a experiência.

Considerando a contribuição das narrativas e histórias para a formação de professores, Reali e Mizukami (2005) realizaram um estudo sobre as escritas de acadêmicas do curso de Pedagogia, após sua inserção em salas de aula, durante um projeto de ensino e aprendizagem que buscou relacionar as disciplinas do curso, como uma alternativa ao paradigma da racionalidade técnica. As reflexões, a partir da investigação, indicaram o potencial formativo e investigativo das narrativas e relacionaram importantes elementos da aprendizagem da docência. Esse estudo tornou-se também uma das fontes inspiradoras da pesquisa aqui apresentada.

\section{Percepções iniciais a partir das narrativas}

A partir do mapeamento e da análise de nove diários, foi possível examinar como as bolsistas (futuras professoras), inicialmente, conceberam a docência, o processo ensino-aprendizagem e a alfabetização; os principais aspectos observados e valorizados; as pistas de um pensamento investigativo e reflexivo. Tais percepções devem ser fundamentais para a problematização das experiências, das pré-concepções, das crenças, das teorizações pessoais, com o propósito de conduzir à investigação sistemática e à análise fundamentada. O exame dos diários possibilitou a organização e definição de alguns temas desencadeadores de reflexão, em função de elementos frequentes e recorrentes nas narrativas.

Um aspecto inerente às observações das bolsistas refere-se às "dificuldades de aprendizagem”. A diversificação dos níveis de aprendizagem dos alunos torna-se um dos principais objetos de questionamento de todas as acadêmicas, independentemente da série em que estão no curso de Pedagogia. Esta questão aparece na indagação de B6, externando sua preocupação com os alunos: "Como ajudá-los e como desenvolver atividades diferenciadas numa turma de trinta alunos?”.

A questão é retratada por outra bolsista, de um modo mais detalhado:

Nessa semana, tive melhor percepção das crianças com maiores dificuldades. $\mathrm{Na}$ primeira semana, me foquei em apenas um menino com grande dificuldade na escrita (naquele momento foi a criança que mais me chamou a atenção). Nessa semana, como ele tinha dificuldade de copiar do quadro, comecei a copiar em seu caderno para que ele copiasse embaixo e obtive algum resultado. Pensei comigo que esse menino precisa de atividades diferenciadas e atenção individual. Mas outras crianças me despertaram a atenção porque também não conseguem assimilar o conteúdo e também têm dificuldades na leitura e na escrita. É óbvio que preciso ajudá-los e desenvolver com eles atividades a partir do nível de cada aluno, mas o 
que trabalhar com esses alunos? Que tipo de atividade desenvolver? Quais os subsídios necessários? Como motivar esses alunos? Sinto-me perdida. (B 9).

A referida acadêmica toma a iniciativa de propor um trabalho com os alunos que apresentam diferenças de aprendizagem mais acentuadas, mesmo afirmando estar insegura quanto ao desenvolvimento deste trabalho. Assim como B9, as demais bolsistas também enfrentam situações dessa natureza e se demonstram comprometidas, trazendo, muitas vezes, para elas próprias uma responsabilidade em relação à aprendizagem dos alunos. Durante suas narrativas, "todas” as bolsistas vão expressando a satisfação que sentem em relação aos avanços de vários alunos, nas diferentes turmas. Nesse sentido, demonstram um dos aspectos inerentes ao trabalho do professor quando do início de suas carreiras, a preocupação com o impacto do ensino nos alunos, ou seja, a preocupação com a aprendizagem e com a relação interpessoal que estabelecem com eles (PACHECO; FLORES, 1999).

A reflexão sobre as dificuldades de aprendizagem, a partir da experiência, desencadeou várias problematizações no contexto do projeto de iniciação à docência: os dilemas referentes ao ensino padronizado; a necessidade de estratégias metodológicas que favoreçam o trabalho com as diferenças de aprendizagem; os pré-conceitos em relação aos alunos; a necessária compreensão sobre os processos cognitivos e sua relação com a apropriação da escrita; a importância da observação e da reflexão do professor sobre o ensino e a aprendizagem; o apoio pedagógico ao trabalho do professor.

No contexto vivenciado, a tematização da prática ocorre por meio do distanciamento durante a escrita de seus diários e as discussões coletivas. Nota-se que, a cada se- mana, o olhar fica mais atento, captando-se o movimento do real. Nesse sentido, as bolsistas articulam elementos que se entrecruzam na docência e no processo de alfabetização. Apontam assim suas percepções sobre o ensino significativo da leitura e da escrita, inferindo que as crianças precisam ser motivadas a perceberem a importância desta aprendizagem para suas vidas (B1, B2, B5, B8). As acadêmicas percebem que quando são trabalhados textos que chamam a atenção das crianças os alunos se envolvem e isso pode favorecer sua aprendizagem. Frequentemente, elas questionam o excesso de cópias e se tal proposta é um encaminhamento válido. Alguns trechos de narrativas demonstram estes aspectos:

Na quinta-feira, a professora verificou a leitura dos alunos. Eram palavras conhecidas deles, que estão nos cartazes da sala e acho que isso não demonstrou a 'real' leitura dos alunos. Penso que se fosse um texto para a criança ler e interpretar, seria mais significativo; nas aulas de Fundamentos da Alfabetização, a professora sempre nos fala para tomarmos cuidado com palavras isoladas, pois fora de contexto, podem parecer 'sem sentido' para a criança. [...] pude perceber que os aspectos referentes ao letramento não são muito explorados, colaborando para uma aprendizagem artificial dos educandos. (B8).

No entanto, as acadêmicas também entram em conflito quando afirmam que é preciso alfabetizar de forma significativa, indicando suas inseguranças e questionamentos. Nesse sentido, demonstram que a observação da experiência gera indagações que envolvem a formação do professor em seus diferentes aspectos, considerando-se atitudes, competências e os diferentes saberes que compõem o conhecimento profissional docente. $\mathrm{O}$ seguinte trecho representa algumas dessas reflexões: 
No livro 'Alfabetizando sem o BA BE BI BO BU’, de Luiz Carlos Cagliari, que foi estudado nas aulas de alfabetização, o autor aborda que no método das cartilhas tudo gira em torno da silabação e isso faz com que o aluno pense que para ler é preciso silabar. Isto faz com que o aluno não compreenda os textos e crie uma dificuldade de expressão. É óbvio que o método sintético limita o conhecimento da criança, mas fico pensando como alfabetizar sem ele. É necessário que o aluno seja o centro e construa seu conhecimento através da mediação do professor, mas nunca vi isto acontecer na prática, em todas as observações que fiz durante o curso, nunca presenciei esta ação. Questiono-me se este professor sabe fazer diferente. $\mathrm{Na}$ sala em que estou a professora é o centro do processo ensino-aprendizagem e os alunos meros copistas. Mesmo assim são poucos com dificuldades de aprendizagem, apenas seis crianças, de vinte e sete alunos. Penso e me pergunto: vinte e uma crianças já sabem ler e escrever, mas será que esta aprendizagem está sendo significativa? Mas como fazer diferente? (B9).

A ludicidade foi outro tema recorrente nos diários, especialmente em relação às classes que possuem crianças que completam seis anos ao longo do ano letivo $\left(1^{\circ}\right.$ ano). As questões abordadas conduziram à discussão sobre a necessidade de compreender a ludicidade como princípio inerente à alfabetização, e não somente como eventos isolados. Outras bolsistas (B6, B8 e B9), que estavam em classes de $2^{\circ}$ e $3^{\circ}$ anos, também afirmam que a criança gosta e precisa brincar em qualquer idade e fase da escolaridade. $\mathrm{O}$ comentário abaixo demonstra este aspecto:

Houve um dia nesta semana que a professora $X$ ficou na nossa sala porque era dia de curso da professora Y. As atividades deixadas eram sobre a letra P. A professora X cantou com eles a música "Lá vem o pato”. As crianças gostaram e isso foi um grande incentivo para a aula. Sinto falta deste tipo de atividade para os alunos, pois eles são crianças, mas às vezes parece que os professores esquecem-se dessa questão e até dizem que "escola não é lugar de brincar”, embora saibamos que para muitas crianças, a escola é o único lugar em que podem brincar. No planejamento de minhas intervenções, estou procurando atividades mais lúdicas, para que os alunos aprendam e se divirtam. (B8).

Durante o mapeamento dos diários, é possível verificar que aparecem os componentes da ação docente, dentre eles a relação planejamento e avaliação. As bolsistas parecem começar a perceber a relação dinâmica e interdependente entre esses aspectos. Apontam, de modo recorrente, a necessidade de planejar em relação ao ritmo e às características de aprendizagem dos alunos. Preocupam-se em participar da hora-atividade com a professora e sentem-se valorizadas quando isso acontece, como enfatiza B7: “A professora está sempre me convidando para planejar com ela em sua hora-atividade e tem sido proveitoso, pois estou aprendendo muito com ela”.

Já B5 procura estabelecer uma relação teórica entre sua observação e a necessidade de planejar, apoiando-se num referencial consultado. Ao mesmo tempo, sob sua ótica, valoriza o trabalho da professora que acompanha:

O planejamento escolar é um processo de racionalização, organização e coordenação da atividade do professor, que articula o que acontece dentro da escola com o contexto em que se insere. É um processo de reflexão crítica a respeito das ações e opções do professor. [...] A professora demonstra compreender o que é um planejamento e a importância dele para a sua prática, realizando seu planejamento num 
caderno e separando por dias. Sempre busca planejar suas aulas voltadas para a realidade dos alunos e também apresentando coisas novas para a classe.

Nesse contexto, as bolsistas observam os elementos da prática docente e questionam o processo de avaliação, compreendendo que este adquire sentido quando demonstra quais são as reais necessidades dos alunos e desencadeia a reflexão sobre o ensino. Algumas acadêmicas (B5, B7, B8) indagam sobre o valor da denominada "avaliação externa”, pois acreditam que esta não tem cumprido seu papel de retornar à escola e ao professor dados que contribuam para repensar a prática pedagógica e redimensionar a alfabetização.

A tarefa escolar, mais especificamente o “dever de casa”, foi outro elemento da prática pedagógica que mereceu destaque e foi objeto de atenção nesta primeira fase de inserção das bolsistas. Nesse sentido, é importante a fala de B4, que inicia uma problematização sobre o assunto:

Ao longo do ano, aparecem muitas dúvidas. Uma das mais significativas para mim foi a questão da tarefa. Até que ponto a tarefa auxilia no processo de aprendizagem dos alunos, uma vez que o contexto em que os alunos estão inseridos é uma questão de bastante influência, já que os pais na maioria dos casos trabalham o dia inteiro e existem casos em que os próprios pais não são alfabetizados? Outro ponto que me chamou a atenção é que a professora não utilizava a tarefa como um recurso de ensino, ou seja, ela passava a tarefa de modo como se aquilo fosse uma obrigação. No outro dia, ela não corrigia e se a criança não tivesse entendido, ficaria sem entender. Muitas vezes, corrigi tarefas a pedido da professora e notava que eram a mãe, irmãos ou outra pessoa qualquer que fazia a atividade para o aluno.
Outro aspecto bastante enfatizado pelas bolsistas refere-se ao contexto que envolve a escola, nas suas dimensões familiares, sociais, culturais, econômicas, políticas. Embora todas as acadêmicas já tenham vivenciado situações de inserção na escola, desde o $1^{\circ}$ ano do curso de Pedagogia, nota-se que sentem o impacto em relação à realidade dos alunos, da escola, do processo ensino-aprendizagem, ao vivenciarem, efetivamente, o cotidiano escolar e seu entorno. Nesse sentido, questões observadas como violência doméstica, abusos de diferentes naturezas, falta de condições básicas de vida, comunidades rodeadas pelo tráfico de drogas, dentre outros problemas tornaram-se temas inquietantes para as futuras professoras (B1; B3; B5; B8). A naturalização frente a questões como o assassinato do pai de um dos alunos ou virar o lixo da escola para buscar comida chamaram a atenção das acadêmicas. Afirmam vivenciar uma realidade que não imaginavam e questionam seu papel profissional e humano neste tipo de sociedade. Assim, perguntam sobre o que fazer para que as crianças usem, de fato, o conhecimento que deve ser abordado na escola, como meio para melhoria de suas vidas.

Dentre as temáticas que mereceram destaque, encontra-se o processo de inclusão das crianças com deficiências de diferentes naturezas no ensino fundamental (B1; B2; B5; B6; B7; B8). Nesse caso, retratam suas observações e demonstram a preocupação em auxiliar no atendimento dos alunos incluídos nas classes de alfabetização. Nessa direção, B6 interroga: "Será que minha formação inicial dará base para trabalhar com a inclusão?" "Será que se aprende mais com a teoria ou só a prática me mostrará o que fazer?”

Observa-se, por meio das narrativas, que as futuras professoras elaboram suas reflexões, apontam possibilidades, expressam 
algumas crenças, realizam questionamentos em função da organização escolar em que estão inseridas, da partilha de experiências, daquilo que representam como correto na ação docente, das discussões e estudos realizados no projeto. Nesse âmbito, a trajetória no curso de Pedagogia também se revela. Os questionamentos e apontamentos realizados, em função do observado e do vivido, são indícios de que os estudos realizados no curso contribuem para provocá-las em direção a uma reflexão mais ampliada sobre a prática docente. Ao mesmo tempo, a vida cotidiana da escola torna-se lugar privilegiado para problematizar e analisar os aspectos que envolvem a docência e o processo ensino-aprendizagem.

As bolsistas também buscam fundamentar mais enfaticamente suas observações na tentativa de trazer à tona os saberes pedagógicos tratados no contexto do curso. Como exemplo disso, B5 busca realizar uma reflexão mais "teórica”, do ponto de vista do conhecimento científico, ao observar um trabalho de discussão e estudo sobre o bairro, proposto pela professora regente e expressa:

Observei que ao questionar sobre o bairro, a professora considerou a Zona de Desenvolvimento Proximal, que é um conceito elaborado por Vygotsky e define a distância entre o nível de desenvolvimento real, determinado pela capacidade de resolver um problema sem ajuda, e o nível de desenvolvimento potencial, determinado através de resolução de um problema sob a orientação de um adulto ou em colaboração com outro companheiro. Ou seja, quando as crianças responderam as questões que a professora realizava, pode-se observar que o conhecimento que já foi apreendido está na zona de desenvolvimento real.

Torna-se importante destacar que as futuras professoras parecem compreender o valor do conhecimento teórico sistematizado, apresentado e abordado na academia, para fundamentar suas observações e vivências. Ressalta-se que os estudos teóricos também são constantes nos encontros periódicos do projeto de iniciação à docência, contribuindo para que as acadêmicas mobilizem alguns saberes da formação, como os saberes pedagógicos e das áreas específicas do ensino (neste caso, a alfabetização), na relação com a experiência. Nessa direção, as acadêmicas revelam as traduções que fazem da teoria ao se defrontarem com a experiência de ensinar e procuram atribuir sentido aos temas e problemas presentes no contexto de trabalho docente.

É interessante analisar, a partir desses dados, que as reflexões realizadas pelas acadêmicas precisam ser compartilhadas pelo coletivo de professores do curso. As concepções por elas construídas necessitam ser problematizadas, discutidas e explicitadas, pois podem ocorrer interpretações errôneas da teoria produzida no âmbito científico, comprometendo o processo de aprendizagem profissional. É necessário o apoio às reflexões, já que vários pontos de vista são desencadeados, a partir da relação dinâmica entre o sujeito e o objeto do conhecimento.

\section{Apontamentos finais: algumas reflexões}

Os dados, oriundos da primeira etapa desta pesquisa, confirmam que a experiência do cotidiano escolar é constituinte do conjunto de saberes do professor e, nesse sentido, é uma fonte significativa de aprendizagem profissional. Na e pela experiência, entrelaçam-se os saberes pessoais, as subjetividades, os esquemas de pensamento, as crenças com os outros conhecimentos, originados nos diferentes contextos que 
envolvem a formação do professor, inserindo-se a formação acadêmico-profissional.

Nessa direção, foi possível perceber que as bolsistas iniciam um contato com professores experientes e com suas necessidades no que se refere à dinâmica do ensino e da aprendizagem. Começam a observar que as professoras já possuem uma base de conhecimento, também pautada em experiências passadas e que estas têm um significado e denotam uma forma de poder sobre o que elas fazem em suas salas de aula. Assim, a observação e a partilha de experiências com outros profissionais são elementos a serem considerados no espaço da formação inicial (acadêmico-profissional). Tal questão nos remete à discussão elaborada por Gimeno Sacristán (1999), de que a experiência, além de se constituir numa cultura pessoal e subjetiva, localiza-se na esfera do conhecimento intersubjetivo e compartilhado, pois pode ser socializada, tornando-se base para ações futuras ou de outros sujeitos.

No entanto, é preciso atentar para o fato de que a experiência por si só não conduz a uma ressignificação adequada da prática pedagógica, promovendo rupturas e avanços no conhecimento do professor. Sem a necessária problematização e análise do saber experiencial, pautadas em diferentes fontes de conhecimento, corre-se o risco de se repetir práticas equivocadas, justificadas pela utilidade imediatista da ação ou pelas crenças originadas e mantidas num dado contexto. É importante lembrar a força que tem o conjunto de experiências que são acumuladas, a partir de uma relação intersubjetiva, no interior das instituições, estabilizando-se uma dada cultura e um tipo de prática educativa, a qual consolida formas de pensar e agir (GIMENO SACRISTÁN, 1999).

Nesse sentido, as bolsistas foram provocadas e encorajadas a observar, tematizar e problematizar as experiências relativas ao processo ensino-aprendizagem no contexto da Alfabetização. Sendo assim, a observação apresenta-se como um processo elementar na construção do conhecimento sobre a docência e esta é uma fase necessária para desencadear processos de reflexão e investigação, daí a necessidade de ser provocada e orientada durante a formação acadêmico-profissional.

No projeto em questão, considera-se a observação inserida num conjunto de processos formativos. Nessa perspectiva, as bolsistas foram instigadas a ver, ouvir e sentir os aspectos referentes ao ensino e aprendizagem dos alunos nas classes de alfabetização. Os dados dos diários demonstraram que o referido exercício possibilitou a descrição de cenas, sujeitos, locais, situações, entre outros, favorecendo a tematização da prática, ou seja, possibilitando o olhar para a sala de aula, de forma a tomá-la como objeto de reflexão. A ideia é que se exercite no futuro profissional um olhar problematizador, no sentido de que este esteja atento às múltiplas dimensões que envolvem uma situação, num dado contexto. Nesse raciocínio, é preciso que o futuro professor aprenda a examinar em que condições um problema se expressa e qual é a sua natureza, para compreender também a partir de que e como intervir nas situações.

Foi possível perceber que as bolsistas exercitaram a atitude de "abertura" frente às situações que observaram, trazendo à tona questões referentes às concepções e formas de ensino mobilizadas pelos professores. Frente às necessidades identificadas, as acadêmicas começam a interrogar a ação. Sendo assim, as situações por elas observadas tornam-se problemas que estimulam o raciocínio em busca de soluções, aspecto inerente a um movimento reflexivo. 
Conclui-se assim que a observação, a tematização e a problematização da experiência são processos articulados e inerentes à prática docente, portanto, devem ser oportunizados durante a formação acadêmico-profissional (inicial) do professor. As narrativas, nesse contexto, são atos significativos de registro da própria vivência, propícios para a avaliação da representação que se possui da prática de outros e da própria prática. Assim, pela narrativa, é possível tornar públicos sentimentos, compreensões, representações e ações. Ainda, ao integrar o processo cognitivo, as narrativas oportunizam um movimento reflexivo de apropriação e explicitação de conhecimentos que o sujeito já possui. Desse modo, tal processo oportuniza que o sujeito amplie sua compreensão e reelabore seus saberes, num movimento entre diferentes fontes de conhecimento. As narrativas são, portanto, estratégias a serem consideradas na formação inicial.

As futuras professoras revelam, em seus diários, percepções sobre a prática docente a partir do enfrentamento de questões no seu campo de exercício profissional. Abordam a complexidade da referida prática, caracterizando a dimensão interativa, contextual e dinâmica da atividade docente, além de refletirem sobre vários elementos do processo ensino-aprendizagem, trazendo à tona suas preocupações e novas perguntas. Nessa perspectiva, o movimento proposto no programa de iniciação à docência provocou a emergência de uma atitude investigativa que foi potencializada numa continuidade de situações formativas, uma vez que, a partir das observações, foi desenvolvido um projeto de investigação-ação, a ser analisado na segunda fase da presente pesquisa.

Confirma-se assim que a atividade reflexiva necessita ser provocada, potencializada e cultivada, por isso se constrói em processo. Além disso, a reflexão necessita estar articulada a processos investigativos na relação com a prática docente, pois quando esta é questionada e investigada, têm-se como consequência alterações nos padrões de pensamento, na compreensão e argumentação. Torna-se possível, assim, uma postura reflexiva frente à profissão e ao contexto em que o ensino se concretiza.

Nesse sentido, as primeiras descobertas indicam enfrentamentos necessários no contexto da formação inicial, o que envolve a ressignificação dos tempos e espaços curriculares destinados à aprendizagem profissional da docência.

\section{Referências}

GIMENO SACRISTÁN, J. Poderes instáveis em educação. Porto Alegre: Artmed, 1999.

IMBERNÓN, F. Formação docente e profissional: formar-se para a mudança e a incerteza. 9. ed. São Paulo: Cortez, 2011.

MIZUKAMI, M. da G. N. et al. Escola e aprendizagem da docência: processos de investigação e formação. São Carlos: EdUFSCar, 2002.

NÓVOA, A. (Org.). Vidas de professores. Porto: Porto Editora, 1991.

Profissão professor. Porto: Porto Editora, 1992.

OLIVEIRA, D. A. Trabalho docente. (Verbete) In: OLIVEIRA, D. A.; DUARTE, A. C.; VIEIRA, L. M. F. (Orgs.). Dicionário: trabalho, profissão e condição Docente. 1 ed. Belo Horizonte: GESTRADO/FAE/UFMG, 2010. v 1, 432 p.

PACHECO, J. A.; FLORES, M. A. Formação e avaliação de professores. Porto: Porto Editora, 1999. 
REALI, A. M. R.; MIZUKAMI, M. G. N. Construindo a base de conhecimento profissional da docência: contribuições do uso de histórias e narrativas. In: REALI, A. M. R.; MIZUKAMI, M. G. N. (Orgs.). Processos formativos da docência: conteúdos e práticas. São Carlos: EdUFSCar, 2005, p. 121-142.

ROLDÃO, M. do C. Função docente: natureza e construção do conhecimento profissional. Revista Brasileira de Educação, v. 12, n. 34, p. 94-181, 2007.

TARDIF, M. Saberes docentes e formação profissional. Petrópolis: Vozes, 2002.

; RAYMOND, D. Saberes, tempo e aprendizagem do trabalho no magistério. Educação e Sociedade. Ano XXI, n.73, p. 209-244, dez. 2000.

VEIGA, I. P. A. Docência como atividade profissional. VEIGA, I. P. A.; D’AVILA, C. M. Profissão docente: novos sentidos, novas perspectivas. Campinas: Papirus, 2008.

ZABALZA, A. Diários de aula: um instrumento de pesquisa e desenvolvimento profissional. Porto Alegre: Artmed, 2004.

ZEICHNER, K. A formação reflexiva de professores: ideias e práticas. Lisboa: Educa, 1993.

ZEICHNER, K.; NOFFKE, S. E. Practitioner research. In: Richardson, V. (Ed.) Handbook of research on teaching. Washington, D. C.: American Educational Research Association, 2001, p. 298-330.

ZEICHNER, K.; PEREIRA, J. D. A pesquisa na formação e no trabalho docente. Belo Horizonte: Autêntica, 2002.

ZEICHNER, K. M. Formando professores reflexivos para a educação centrada no aluno: possibilidades e contradições. In:
BARBOSA. R. L. L. (Org.). Formação de educadores: desafios e perspectivas. São Paulo: UNESP, 2003.

Enviado em: 30/09/2012

Aceito em: 02/12/2012 